\title{
Elevated Pancreatic Enzymes and Acute Pancreatitis in Subjects with Type 2 Diabetes Mellitus Treated with Exenatide
}

\author{
Sonal Banzal and Udaya M Kabadi* \\ Central Iowa Veterans Health System, Broadlawns Medical Center, University of Iowa, USA
}

Submission: February 09, 2017; Published: February 23, 2017

"Corresponding author: Udaya M Kabadi MD, FACP, FRCP (C), FACE, University of Iowa, Iowa City, IA 52242, USA, Tel: 13195948575 ; Email: ukabadi@gmail.zom

Abstract

Background: Acute pancreatitis is listed as an adverse effect of exenatide [EX] by the regulatory agencies. However, the prevalence of acute pancreatitis is reported to be variable in multiple clinical trials and Meta analyses.

Methods: Retrospective comparative analysis was conducted for incidence of acute pancreatitis in 164 subjects with type 2 Diabetes Mellitus administered Exenatide and age and weight matched 150 subjects receiving Metformin and SU glipizide.

Results: In 50 subjects, EX was discontinued, one because of persistent chest pain and 49 because of onset of severe nausea or/and vomiting. Thirty nine subjects also complained of abdominal pain. In 35 of these, serum amylase and lipase were elevated. However, abdominal CT scan confirmed presence of acute pancreatitis in 14 subjects ( $8.5 \%$ ) with no apparent pancreatic abnormality being noted in the remaining 21 subjects $(12.8 \%)$. Acute pancreatitis as established by the same diagnostic criteria occurred in 4 subjects $(2.7 \%)$ treated with Metformin and Glipizide $(\mathrm{p}<0.01)$. Abdominal pain, nausea and vomiting resolved with simultaneous normalization of pancreatic enzymes in all subjects following treatment recommended for acute pancreatitis.

Conclusion: Therefore, the incidence of acute pancreatitis confirmed by abdominal CT scan is increased $>3$ fold in subjects with type 2 Diabetes Mellitus administered exenatide when compared with subjects treated with Metformin and Glipizide. Moreover, elevated pancreatic enzymes without diagnostic abdominal CT findings in many subjects administered exenatide may indicate presence of pancreatitis in the early stage of the disorder although requiring further examination.

Keywords: Effect of exenatide [EX]; Abdominal CT scan

\section{Introduction}

Regulatory agencies worldwide including FDA have continued to list acute pancreatitis as an adverse effect of GLP 1 analogs including exenatide despite post marketing studies and Meta analyses indicating variable incidence [1-5]. However, in many of the initial clinical trials, data regarding serum concentrations of pancreatic enzymes in subjects on onset of abdominal pain, nausea and vomiting was not provided thus possibly missing the diagnosis of acute pancreatitis. Moreover, a plausible mechanism of occurrence of acute pancreatitis following administration of these agents has not been discussed. Therefore, retrospective analysis was conducted for examining the incidence of acute pancreatitis in subjects administered GLP1 analog exenatide and compared with its incidence in subjects treated with Metformin and SU Glipizide.

\section{Subjects and Methods}

This retrospective analysis examined the incidence of acute pancreatitis on administration of exenatide in subjects with type 2 diabetes Mellitus. 164 consecutive obese (BMI levels $>30 \mathrm{~kg} /$ $\mathrm{m} 2$ ) adult subjects, 126 men and 38 women (ages 34- 76 years) with history of type 2 Diabetes Mellitus and HbA1c levels, 7.59.5\% and desirable fasting plasma glucose concentration, 80-130 $\mathrm{mg} / \mathrm{dl}$ while receiving metformin, glipizide and insulin glargine between January 2011 and December 2013 and initiated on sc. exenatide $5 \mathrm{mcg}$ twice daily to attain and maintain postprandial glycemic control are included in this analysis. The diagnosis of type 2 diabetes was confirmed by fasting serum C-peptide concentration $>1 \mathrm{ng} / \mathrm{dl}$. 
The dose of sc. exenatide was increased to $10 \mathrm{mcg}$ twice daily after 4 weeks if subjects tolerated the initial dose. The incidence of acute pancreatitis in age and weight matched subjects with type 2 Diabetes Mellitus treated with metformin and glipizide was used for comparison. The duration of therapy in both groups of at least 6 months was deemed to be appropriate for comparison. Exclusion criteria of our study were prior history of acute pancreatitis, gall bladder disease, gastroparesis and allergic reaction to any GLP1 analog. Subjects with creatinine $>1.5 \mathrm{mg} / \mathrm{dl}$, liver enzymes $>2.5$ time's upper limit of normal, serum triglycerides $>500 \mathrm{mg} / \mathrm{dl}$ and pregnant women were excluded as well.

All the subjects in both groups were being treated with either ACE inhibitor Lisinopril or ARB Losartan for management of hypertension and/or for renal protection as well as a statin, Atorvastatin or Rosuvastatin for dyslipidemia and/or cardio protection. Subjects over 50 years of age were also administered aspirin $81 \mathrm{mg}$ daily in absence of contraindications, e.g. history of bleeding or a bleeding disorder. Laboratory tests were determined using well established commercial kits by the local laboratory at the medical center where the study was conducted. The statistical comparison between the incidence of acute pancreatitis in subjects with type 2 diabetes mellitus administered exenatide on one hand and subjects treated with metformin and Glipizide on the other was conducted by multivariate analysis with determination of the relative risk odds ratio.

\section{Results}

In 42 subjects, exenatide was discontinued within 1-3 weeks after initiation with $5 \mathrm{mcg}$ twice daily, one because of persistent chest pain and 41 because of onset of severe nausea or/and vomiting. Exenatide was discontinued in another 8 subjects due to onset of the same symptoms within a week after increasing the dose to $10 \mathrm{mcg}$ twice daily. Thirty nine of these 49 subjects also complained of abdominal pain and In 35 of these, serum amylase and lipase were elevated $>2 \mathrm{x}$ highest normal concentration indicative of pancreatitis whereas in the remaining 14 subjects, these enzyme concentrations were normal.

However, abdominal CT scan confirmed presence of acute pancreatitis in 14 subjects $(8.5 \%)$ with no apparent pancreatic abnormality being noted on CT scan in the remaining 21 subjects $(12.8 \%)$. Acute pancreatitis as established by onset of acute abdominal pain, elevated pancreatic enzymes and abdominal CT scan occurred in 4 of 150 subjects (2.7\%) treated with metformin and glipizide (RR 3.2, confidence interval, 2-13- 4.37; $\mathrm{p}<0.01 \mathrm{vs}$. exenatide). The relative risk remained significant (3.0, confidence interval, 1.82-4.16; $\mathrm{p}<0.01$ ) after elimination of other factors namely, HbA1c, age, duration of diabetes, serum triglycerides and liver enzymes by multivariate analysis.

Serum pancreatic enzymes were not determined in any remaining subjects treated with metformin and glipizide because of lack symptoms, e.g. nausea, vomiting and/ or abdominal pain. All subjects were treated with therapy recommended for acute pancreatitis including discontinuation of oral intake, intravenous infusion of normal saline as well as dextrose and parenteral administration of drugs for relief of pain. Abdominal pain, nausea and vomiting resolved within 3-5 days and normalization of pancreatic enzymes ensued within 7-10 days.

\section{Discussion}

Acute pancreatitis in subjects in this study was attributed to exenetide since other known causative factors, e.g. alcohol, gall bladder disease, trauma, tumour, peptic ulcer disease, hyperparathyroidism etc. were excluded. Moreover, the study also demonstrates 3 fold increase in the incidence of acute pancreatitis confirmed by history, physical examination and elevated serum pancreatic enzymes in subjects with type 2 diabetes treated with exenatide in comparison to subjects administered metformin and glipizide. The incidence is further exaggerated if the subjects with elevated serum amylase and lipase concentrations with symptoms diagnostic are included in the analysis.

Lack of acute pancreatitis diagnostic evidence on abdominal CT scan may be attributed to the presentation in the early stage of the disorder. This finding is consistent with several case reports as well as documentation in some clinical trials and Meta analyses and animals [6-18]. However, other Meta analyses and another animal study refute this conclusion [1-5,19-22].

The discrepancy and variability of these conclusions may be attributed to the differences in the documentation of concentrations of serum pancreatic enzyme in these reports. In many clinical trials, serum pancreatic enzymes were not reported probably because of lack of assessment despite onset and persistence of characteristic symptoms of acute pancreatitis, e. g abdominal pain, nausea and vomiting. We believe that Meta analyses describing lack of increase in incidence of acute pancreatitis may have included these same clinical trials to arrive at the discrepant conclusion. Finally, the rise in pancreatic enzymes is well documented in several clinical trials and animal studies [23,24].

Despite the variability of conclusions by individual reports, many regulatory agencies continue to mention acute pancreatitis as a major adverse event in the 'prescription information' document for all GLP1 analogs including exenatide [1-5]. This alert regarding these drugs may be attributed to several case reports in the literature describing serious nature of the presentation of acute pancreatitis as well as the data in animals [6-18], thus, the occurrence of acute pancreatitis on administration of GLP1 analogs including exenatide is adequately established as documented in this report.

However, the data regarding the pathophysiology of the disorder is sparse. Delay in pancreatic ductal empting similar to 
the gastric empting, a well established effect induced by GLP1 analogs including exenatide may contribute to stagnation of pancreatic secretions leading to inflammation. Moreover, this mechanism is likely to be exacerbated in subjects with type 2 diabetes manifesting autonomic neuropathy involving pancreas causing asynchronicity between the sphincter of Oddie and pancreatic ductal musculature similar to gastro paresis [25-29].

The rise in pancreatic enzymes may be attributed to the same mechanism as well. However, none of the clinical trials or case reports describes presence of autonomic dysfunction or even peripheral neuropathy in subjects manifesting acute pancreatitis. Unfortunately, testing for autonomic dysfunction was not conducted in subjects in our study as subjects with symptoms of gastroparesis were excluded. Thus, acute pancreatitis following administration of these drugs may be consistent with 'acalculus pancreatitis known to occur in subjects with diabetes mellitus and elderly.

Therefore, in conclusion, subjects manifestation abdominal pain, nausea and vomiting on administration of GLP1 analogs including exenatide must be evaluated by appropriate testing for presence of acute pancreatitis and then managed by recommended therapy as per the alert issued by regulatory agencies. Moreover, future exposure to any GLP1 analogs must be avoided in these subjects.

\section{References}

1. Raschi E, Piccinni C, Poluzzi E, Marchesini G, De Ponti F (2013) The association of pancreatitis with antidiabetic drug use: gaining insight through the FDA pharmacovigilance database. Acta Diabetol 50(4): 569-577.

2. Ryder RE (2013) The potential risks of pancreatitis and pancreatic cancer with GLP-1-based therapies are far outweighed by the proven and potential (cardiovascular) benefits. Diabet Med 30(10): 11481155.

3. Giorda CB, Sacerdote C, Nada E, Marafetti L, Baldi I, Gnavi R (2015) Incretin-based therapies and acute pancreatitis risk: a systematic review and meta-analysis of observational studies. Endocrine 48(2): 461-471.

4. Consoli A, Formoso G (2015) Potential side effects to GLP-1 agonists: understanding their safety and tolerability. Expert Opin Drug Saf 14(2): 207-218.

5. Drab SR (2016) Glucagon-Like Peptide-1 Receptor Agonists for Type 2 Diabetes: A Clinical Update of Safety and Efficacy. Curr Diabetes Rev 12(4): 403-413

6. Denker PS, Dimarco PE (2006) Exenatide (exendin-4)-induced pancreatitis: a case report. Diabetes Care 29(2): 471.

7. Tripathy NR, Basha S, Jain R, Shetty S, Ramachandran A (2008) Exenatide and acute pancreatitis. J Assoc Physicians India 56: 987-988.

8. Ayoub WA, Kumar AA, Naguib HS, Harris Taylor (2010) Exenatideinduced acute pancreatitis. Endocr Pract 16(1): 80-83.

9. Iyer SN, Drake AJ, West RL, Mendez CE, Tanenberg RJ (2012) Case report of acute necrotizing pancreatitis associated with combination treatment of sitagliptin and exenatide. Endocr Pract 18(1): 10-13.

10. Garg R, Chen W, Pendergrass M (2010) Acute Pancreatitis in Type 2 Diabetes Treated With Exenatide or Sitagliptin Diabetes Care 33(11): 2349-2354.
11. Anderson SL, Trujillo JM (2010) Association of pancreatitis with glucagon-like peptide-1 agonist use. Ann Pharmacother 44(5): 904909.

12. Elashoff M, Matveyenko AV, Gier B, Elashoff R, Butler PC (2011) Pancreatitis, pancreatic, and thyroid cancer with glucagon-like peptide1-based therapies. Gastroenterology 141(1): 150-156.

13. Wenten M, Gaebler JA, Hussein M, Pelletier EM, Smith DB, et al. (2012) Relative risk of acute pancreatitis in initiators of exenatide twice daily compared with other anti-diabetic medication: a follow-up study. Diabet Med 29(11): 1412-1418.

14. Macconell L, Brown C, Gurney K Han J (2012) Safety and tolerability of exenatide twice daily in patients with type 2 diabetes: integrated analysis of 5594 patients from 19 placebo-controlled and comparatorcontrolled clinical trials. Diabetes Metab Syndr Obes 5: 29-41.

15. Romley JA, Goldman DP, Solomon M, McFadden D, Peters AL (2012) Exenatide therapy and the risk of pancreatitis and pancreatic cancer in a privately insured population. Diabetes Technol Ther 14(10): 904911.

16. Alves C, Batel-Marques F, Macedo AF (2012) A meta-analysis of serious adverse events reported with exenatide and liraglutide: acute pancreatitis and cancer. Diabetes Res Clin Pract 98(2): 271-284.

17. Faillie JL, Babai S, Crépin S, Bres V, Laroche ML, et al. (2014) Pancreatitis associated with the use of GLP- 1 analogs and DPP-4 inhibitors: a case/ non-case study from the French Pharmacovigilance Database. Acta Diabetol 51(3): 491-497.

18. Dore DD, Hussein M, Hoffman C, Pelletier EM, Smith DB, et al. (2013) A pooled analysis of exenatide use and risk of acute pancreatitis. Curr Med Res Opin 29(12): 1577-1586.

19. Cohen D (2013) Two drugs for type 2 diabetes seem to raise risk of acute pancreatitis, study shows. BMJ 346: f1304.

20. Iyer SN, Tanenberg RJ, Mendez CE, West RL, Drake AJ (2013) Pancreatitis associated with incretin-based therapies. Diabetes Care 36(4): e49.

21. Singh S, Chang HY, Richards TM, et al. (2013) Glucagonlike peptide 1-based therapies and risk of hospitalization for acute pancreatitis in type 2 diabetes mellitus: a population-based matched case-control study. JAMA Intern Med. 173(7): 534-539.

22. Li X, Zhang Z, Duke J (2014) Glucagon-like peptide 1-based therapies and risk of pancreatitis: a self-controlled case series analysis. Pharmacoepidemiol Drug Saf 23(3): 234-239.

23. Yu X1, Tang H, Huang L, Yang Y, Tian B, Yu C (2012) Exenatide-induced chronic damage of pancreatic tissue in rats. Pancreas 41(8): 12351240.

24. Dore DD, Bloomgren GL, Wenten M Hoffman C, Clifford CR, et al. (2011) A cohort study of acute pancreatitis in relation to exenatide use. Diabetes Obes Metab 13(6): 559-566.

25. Li L, Shen J, Bala MM, Shen J, Xin S (2014) Incretin treatment and risk of pancreatitis in patients with type 2 diabetes mellitus: systematic review and meta-analysis of randomised and non-randomised studies. BMJ 15(2): 348:2366.

26. Smits MM, Tonneijck L, Muskiet MH, Kramer MH, Diamant M, et al. (2016) Glucagon-like peptide-1 receptor agonist exenatide has no acute effect on MRI-measured exocrine pancreatic function in patients with type 2 diabetes: a randomized trial. Diabetes Obes Metab 18(3): 281-288.

27. Mondragon A, Davidsson D, Kyriakoudi S, Bertling A, Gomes-Faria R, et al. (2014) Divergent effects of liraglutide, exendin-4, and sitagliptin on beta-cell mass and indicators of pancreatitis in a mouse model of hyperglycaemia. PLoS One 9(8): e104873. 
28. Lando HM, Alattar M, Dua AP (2012) Elevated amylase and lipase levels in patients using glucagonlike peptide-1 receptor agonists or dipeptidyl-peptidase-4 inhibitors in the outpatient setting. Endocr Pract 18(4): 472-477.
29. Smits MM, Tonneijck L, Muskiet MH, Diamant M1, Kramer MH, et al. (2016) Acute plasma amylase increase after glucagon-like peptide -1 receptor agonist exenatide administration in Type 2 diabetes. Diabet Med 9.

\section{Your next submission with JuniperPublishers will reach you the below assets}

- Quality Editorial service

- Swift Peer Review

- Reprints availability

- E-prints Service

- Manuscript Podcast for convenient understanding

- Global attainment for your research

- Manuscript accessibility in different formats ( Pdf, E-pub, Full Text, audio)

- Unceasing customer service

Track the below URL for one-step submission https://juniperpublishers.com/online-submission.php 